\title{
Factors affecting the use of contraception by postnatal mothers at komfo anokye teaching hospital, kumasi, ghana
}

\author{
Article by Emmanuel O. Chukwu ${ }^{1}$, Olive C. Ibeto ${ }^{2}$, Gift A. Nnadi ${ }^{3}$, Habu Haruna ${ }^{4}$ \\ ${ }^{1,2}$ School of Nursing Mkar, Gboko. \\ ${ }^{3}$ Department of Nursing Science, Kwame Nkrumah University of Science and Technology, \\ Kumasi. \\ ${ }^{4}$ Department of Nursing Science, College of Medical Science, University of Maiduguri. \\ Email:-emmanwaguy42@yahoo.com
}

\begin{abstract}
This is a cross-sectional descriptive study which sought to identify the factors that affects the use of contraception among postnatal mothers in Komfo Anokye Teaching Hospita(KATH), Kumasi, Ghana. Purposive and convenience sampling methods were used to select the directorates and health workers respectively. Self-structured and validated questionnaires were administered to 200 postnatal mothers at KATH. Data collected was processed and analysed with Statistical Package for Social Sciences and Microsoft Excel. Results obtained showed that mothers' education and marital status are the main factors affecting the use of family planning. Education exposes the mothers to information on methods of birth control and increases understanding on various aspects of contraceptives such as mechanism of action, method specific instructions and side effects. The years spent in school also delay start of childbearing and enable the women to make informed decisions in matters affecting their reproductive health at a mature age. Marriage exposes mothers to sexual intercourse in the postpartum period and increases the risk of conception. Consequently, the married mothers have a higher intention to use postpartum family planning than their unmarried counterparts. This means that their needs for post-partum family planning (PPFP) should be addressed to ensure their intentions translate into actual use, which will reduce the unmet need for PPFP in KATH.
\end{abstract}

Keywords: Factors, Contraception, Postnatal mothers.

\section{Introduction}

Concerted efforts have been made by the Ghana government through the Ministry of Health and the development partners to meet the contraceptive need of postpartum mothers through training of health workers and integration of family planning services to the maternal and child health services. Despite the identified efforts, the proportion of postpartum women using contraception is still low. This postpartum period presents a rising risk of unwanted conception and often frustrated desire for contraceptive protection (Ross and Winfrey, 2001; Depineres, Blumenthal and Diener-West, 2005). The risk is even greater among the first time mothers who do not know what to expect after their first delivery and rely on the advice and explanations from their female relatives, neighbours and friends (Salway and Nurani, 1998). Although the unmet need for postpartum family planning is high, factors affecting the use of postpartum contraception among the postnatal mothers are not fully known and this calls for such investigation in Ghana. The main purpose of the study is to establish factors that affects the use of postpartum family planning among postnatal mothers in KATH. 
South American Journal of Clinical Research

Special Edition 2016

\section{Methodology}

\section{Study Area}

This study was conducted at the Komfo Anokye Teaching Hospital,(KATH) Ghana, a 1000bed teaching hospital in Kumasi. The hospital is accredited for postgraduate training by the West African college of surgeons. It also provides clinical training for students of nursing, midwifery, emergency nursing, anaesthesia, ear nose and throat, pharmacy and medical laboratory technologists. KATH is bounded on the north by the central police barracks, south and west by $4 \mathrm{BN}$ of infantry Uddara barracks and on the east by the main Bantama-Kejetia dual carriage way. KATH is located in Ashanti region, Southern Ghana. The hospital is divided into clinical and non-clinical directorates. The study was conducted in the clinical directorate of obstetrics and gynecology.

\section{Study Population}

The study population consists of all the postnatal mothers who attends postnatal care at KATH. By approximation, the number of these mothers was1000.

\section{Study Type and Design}

The study was a cross sectional descriptive study to ascertain the factors that affects the use of postpartum contraception among postnatal mothers. 200 women receiving postnatal services from KATH and were willing to participate in the study were used. The questionnaires was administered after an informed consent was obtained from the respondents. Sampling and data collection was done at the directorates of postnatal, obstetrics and gynecology in the KATH.

\section{Data Collection Tools and Techniques}

Data for the study was collected by administering a structured and validated questionnaire from research investigators to patients at the postnatal, obstetrics and gynecology units. The questionnaire was made up of both closed and open ended questions so that respondents can provide adequate responses. For respondents who do not understand the English language, a conscious effort was made by the investigators to get an interpreter to explain the questions in the local language for easy understanding.

\section{Sampling Method and Sample Size}

Convenient sampling was used. Subjects were included in the study upon their willingness to take part in the study after the rationale of the study had been explained to them and confidentiality reiterated. A total of 200 subjects were studied.

\section{Data Processing and Analysis}

Total of 200 questionnaire were distributed and returned completely filled and were analysed. Data collected was analyzed quantitatively with statistical package for social sciences version 16.0 SPSS and Microsoft Excel 2010 was used to analyze and compute statistical data. Analytical techniques used involved the use of descriptive statistics such as frequency distribution and percentages. Data were then presented using tables, bar and pie charts.

\section{Ethical consideration}

Information obtained from subjects was for research only and was treated as strictly confidential; hence, study participants were not required to provide their names on the questionnaire. Participation in this study was voluntary after explaining the rationale and procedures of the study to eligible participants. Also, participants who decide not to participate in 
the survey were not coarsed but allowed to do so. The researchers also ensured that the rights of the study participants were respected.

Clearance was sought from the research and development unit of the Komfo Anokye Teaching Hospital and the committee on human research publications and ethics of the Kwame Nkrumah University of Science and Technology.

\section{Results}

Demographic and Socio-Economic Characteristics

\section{Age of respondents}

Table 1. Age distribution of participants

\begin{tabular}{|l|l|l|}
\hline AGE & Frequency & Percentage (\%) \\
\hline $15-19$ & 22 & 11 \\
\hline $20-24$ & 46 & 23 \\
\hline $25-29$ & 40 & 20 \\
\hline $30-34$ & 54 & 27 \\
\hline $35-39$ & 24 & 12 \\
\hline $40+$ & 14 & 7 \\
\hline TOTAL & $\mathbf{2 0 0}$ & $\mathbf{1 0 0}$ \\
\hline
\end{tabular}

Source: Author's field survey, March, 2014

The age of the respondents ranged from 15 to 49 years. The majority of the respondents were women aged 30-34 years (27\%), followed by young adults aged $20-24$ years (23\%). The oldest women in the sample were aged $40+$ years and formed the lowest proportion of 7 percent.

\section{Religion}

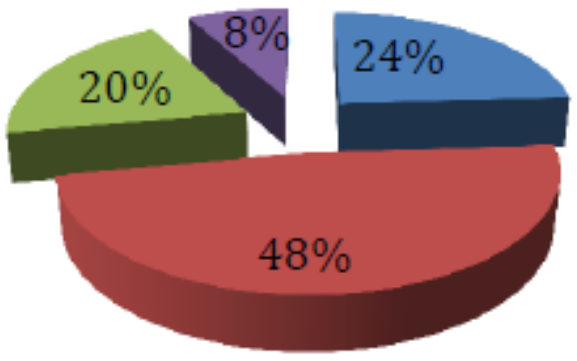

Catholic

Proestant

Muslim

Others

Figure 1. A diagram showing the religious distribution of the respondents

Source: Author's field survey, March, 2014

Religious institutions influence contraceptive use among their followers. Some support while others oppose use of contraceptives to regulate fertility. Figure 1shows that a large majority of the respondents were Protestants (48\%), followed by the Catholics with 24 percent and the Muslims accounting for only 20 percent. 
South American Journal of Clinical Research

Special Edition 2016

\section{Occupation}

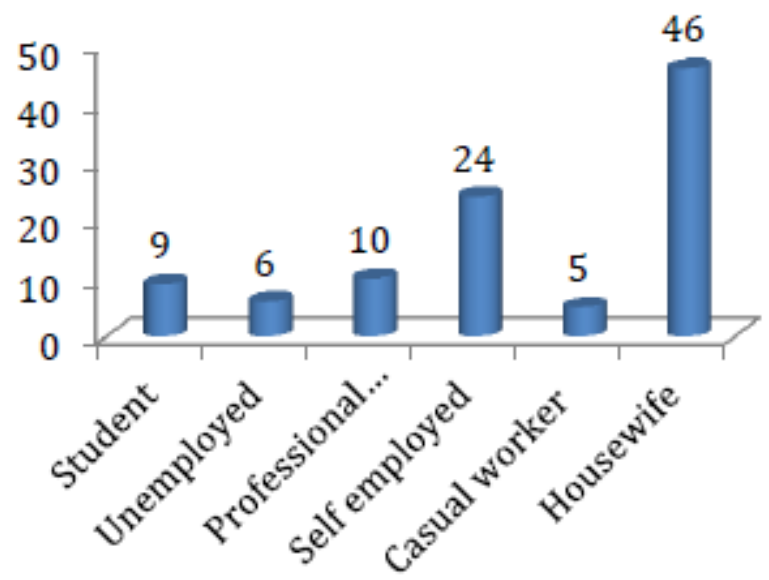

Number of respondents

(\%)

Figure 2. Occupation of respondents

Source: Author's field survey, March, 2014

Figure 2 shows that the majority of the mothers were housewives accounting for 46percent, followed by self-employed (24\%). About 10 percent were professionals while 9 percent were still in school at various levels. Only 6 percent were unemployed and 5 engaged in casual jobs.

Marital status

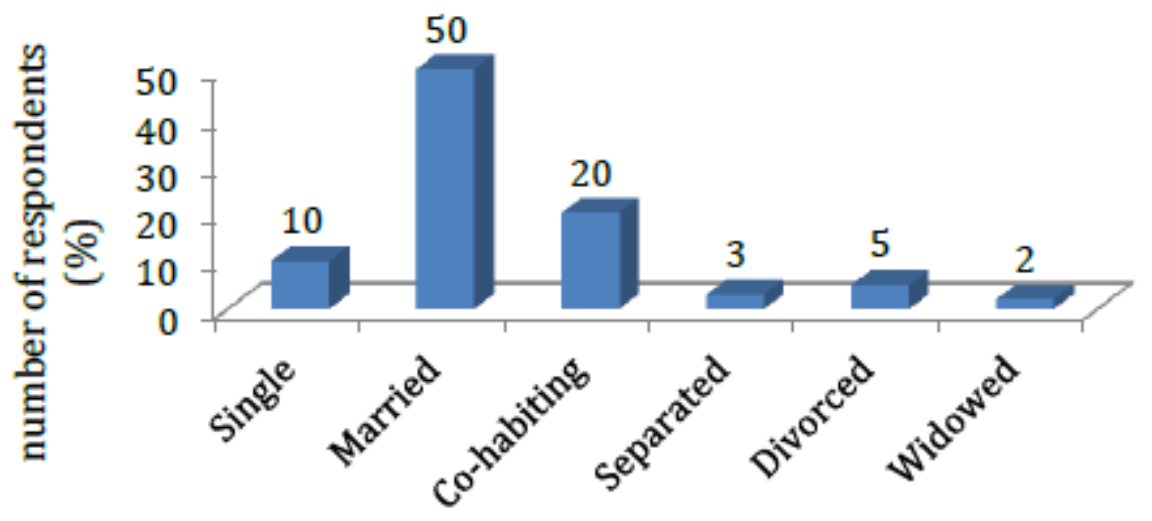

marital status

Figure3. Marital status of respondents

Source: Author's field survey, March, 2014

Figure 3 shows that a high proportion (50\%) of the respondents were married while ten percent were single. A good proportion of respondents was co-habiting(20\%). 


\section{Education level}

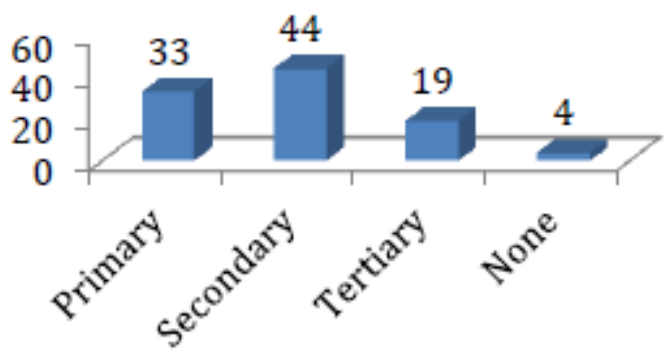

Number of Respondents (\%)

Figure 4. A diagram showing the level of education of respondents

As observed above, almost half of the respondents (45\%) had attained secondary level education, followed by a third of respondents with primary level education. Only less than a fifth (19\%) had ever reached tertiary level and only 4 percent had no education.

\section{General Knowledge On Family Planning}

Knowledge of respondents on the number of contraceptive methods

Table 2: Number of contraceptive methods known by respondents

\begin{tabular}{|l|l|l|}
\hline $\begin{array}{l}\text { No of contraceptive } \\
\text { methods known }\end{array}$ & Frequency & Percentage (\%) \\
\hline 0 & 0 & 0 \\
\hline 1 & 120 & 60 \\
\hline 2 & 44 & 22 \\
\hline 3 & 16 & 8 \\
\hline 4 & 10 & 5 \\
\hline 5 & 6 & 3 \\
\hline 6 & 4 & 2 \\
\hline Total & $\mathbf{2 0 0}$ & $\mathbf{1 0 0}$ \\
\hline
\end{tabular}

Source: Author's field survey, March, 2014

The above table 2 shows that almost all the postnatal mothers (60\%) knew at least one modern contraceptive method. The table also shows that the number of methods known ranged from none to six with a mode of two methods known by almost a fourth of the respondents (22\%).

\section{Source of Information}

From our study, the most frequent source of information about family planning is health talks in the clinics (38\%), followed by community health workers (24\%) and from peers (20\%). The mass media and other books (18\%).

Table 3: showing sources of information

\begin{tabular}{|l|l|l|}
\hline $\begin{array}{l}\text { SOURCES OF } \\
\text { INFORMATION }\end{array}$ & FREQUENCY & PERCENTAGE (\%) \\
\hline Health Talk & 76 & 38 \\
\hline Community Health Workers & 48 & 24 \\
\hline
\end{tabular}


South American Journal of Clinical Research Special Edition 2016

\begin{tabular}{|l|l|l|}
\hline Peers & 40 & 20 \\
\hline Mass media and books & 36 & 18 \\
\hline TOTAL & 200 & 100 \\
\hline
\end{tabular}

Source: Author's field survey, March, 2014

Prior contraceptive use

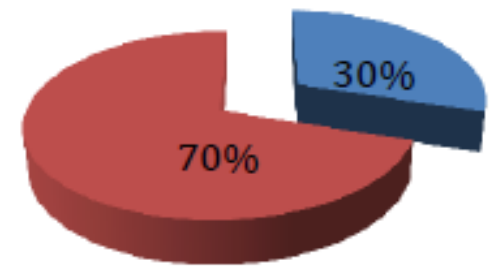

Yes

No

Figure 5. A diagram of the prior usage of contraceptives by respondents Source: Author's field survey, March, 2014

Less than one-third of the respondents (30\%) had used family planning while most of the mothers (70\%) reported not having used contraceptives.

Specific contraceptive methods used

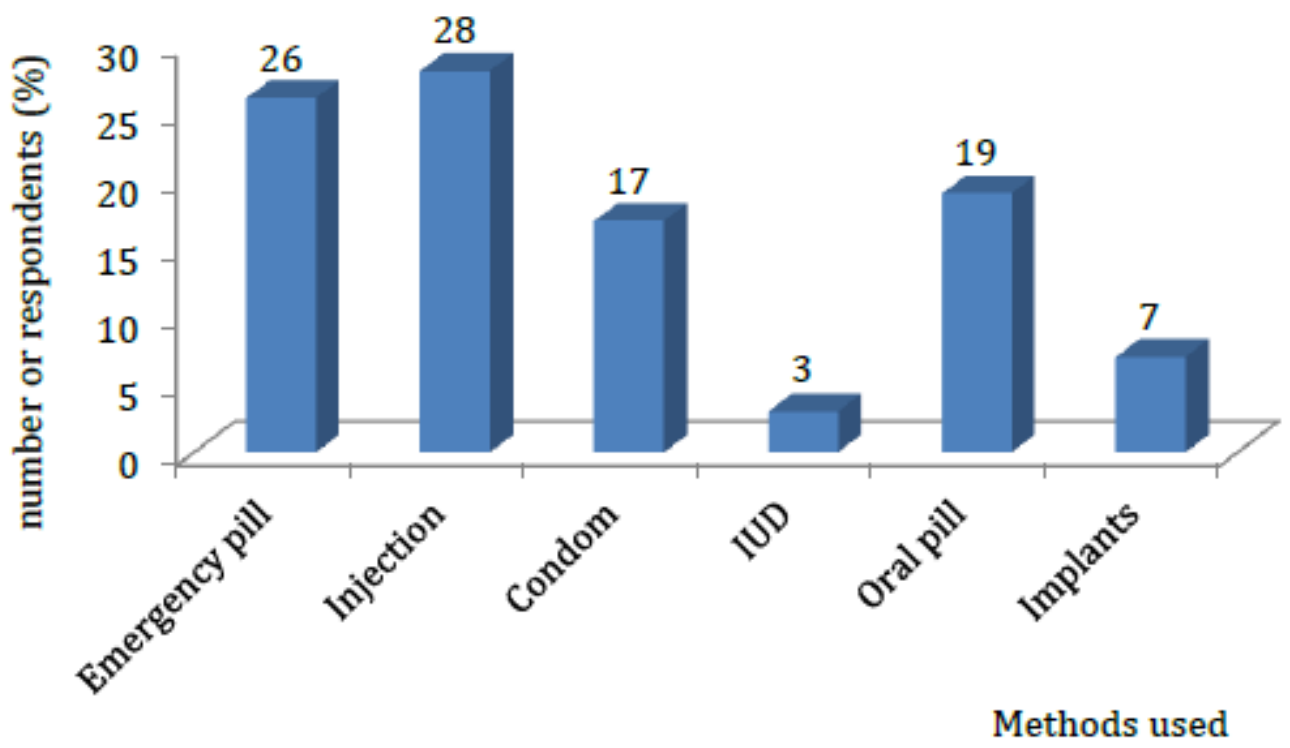

Figure 6. Specific contraceptive methods used by respondents

Source: Author's field survey, March, 2014

About 28 percent of the mothers who reported prior use of contraceptives had used emergency contraceptive, followed by injection (26\%) and oral pills (19\%). Only 17 percent reported use of condom to prevent conception.

\section{Reasons for stoppage}




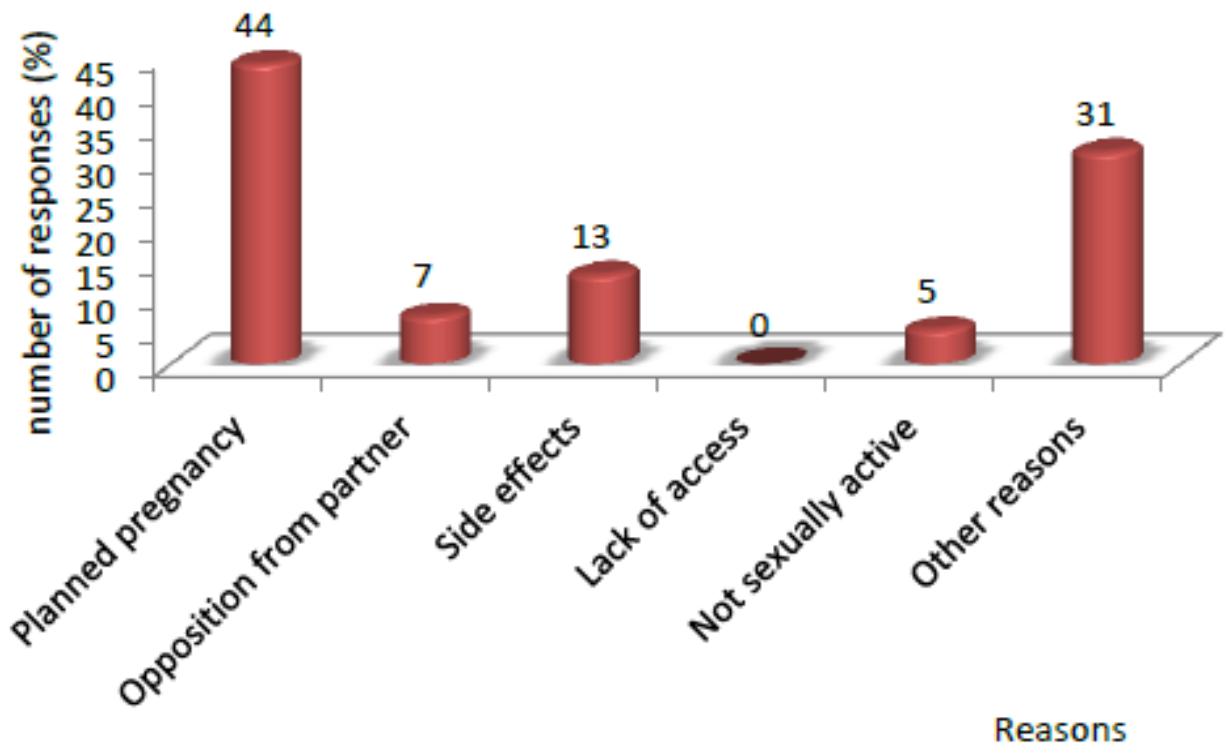

Figure 7. Reasons for stopping contraceptive use.

Source: Author's field survey, March, 2014

Asked why they stopped using the methods, $44 \%$ of the respondents with prior use of contraceptives had plans to conceive while 13 percent cited side effects. About 31 percent were using the contraceptive methods for occasional protection especially emergency pill while opposition from the partner accounted for only 7 percent. Those who reported not being sexually active were about 5 percent.

\section{Prenatal Contraceptive Counseling}

\section{Antenatal attendance}

Table 4: Number of antenatal attendance by respondents

\begin{tabular}{|l|l|l|}
\hline ANC attendance & Frequency & Percentages(\%) \\
\hline None & 6 & 3 \\
\hline Once & 14 & 7 \\
\hline Twice & 20 & 10 \\
\hline Thrice & 40 & 20 \\
\hline Four and above & 120 & 60 \\
\hline Total & 200 & 100 \\
\hline
\end{tabular}

Source: Author's field survey, March, 2014

The table above shows that only 3 percent had not attended antenatal care. It is notable that 60 percent had attended the recommended four or more antenatal care sessions, followed by 30.4 
South American Journal of Clinical Research Special Edition 2016

percent who attended antenatal care three times, 8.3 percent attended twice and 6.9 percent care only once.

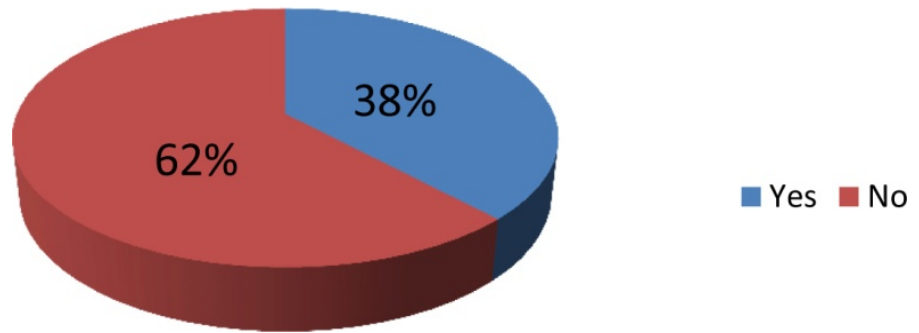

Figure 8: Contraceptive counseling during ANC

Source: Author’s field survey, March, 2014

\section{Prenatal contraceptive counseling}

It is interesting to note that despite the opportunity presented by the high ANC attendance, less than half (38\%) of the postnatal mothers had been given any information about PPFP during the antenatal visit as shown above. This shows that the majority (62\%) of the postnatal mothers had not been given any information on postpartum contraception during the antenatal visits.

\section{PPFP initiation period advised during ANC}

Table 5: PPFP initiation period advised during ANC

\begin{tabular}{|l|l|l|}
\hline $\begin{array}{l}\text { PPFP initiation period advised during } \\
\text { ANC }\end{array}$ & Frequency & $\begin{array}{l}\text { Frequency } \\
\text { Percentages } \\
\mathbf{( \% )}\end{array}$ \\
\hline Less than 6 weeks after delivery & 10 & 5 \\
\hline At 6 weeks after delivery & 110 & 55 \\
\hline More than 6 weeks following delivery & 20 & 10 \\
\hline Not advised & 34 & 17 \\
\hline Forgotten & 26 & 13 \\
\hline Total & 200 & 100 \\
\hline
\end{tabular}

Source: Author’s field survey, March, 2014

$55 \%$ of the mothers who reported having received information on PPFP from the health workers were advised to adopt PPFP at 6 weeks after delivery, followed by 17\% who were not advised and 13\% forgot the time they were advised to adopt PPFP while 5 percent were advice to start PPFP before 6 weeks after delivery. Only 10 percent reported to have been advised to adopt PPFP after 6 weeks following delivery. 


\section{Percieved risk of pregnancy during postpartum period}

\section{Plan to have the pregnancy}

A large majority (72\%) of the mothers reported that they had planned to have the pregnancy. However, a sizeable proportion (28\%) of the mothers reported that they had not planned for the pregnancy and that it was accidental.

Table 6: Plan to have pregnancy

\begin{tabular}{|l|l|l|}
\hline Plan to have the pregnancy & Frequency & Percentages (\%) \\
\hline Planned & 144 & 72 \\
\hline Unplanned & 56 & 28 \\
\hline Total & $\mathbf{2 0 0}$ & $\mathbf{1 0 0}$ \\
\hline
\end{tabular}

The above table 6 shows that $72 \%$ of the respondents planned to have thire pregnancy while $28 \%$ never intended to have the pregnancy.

\section{Preferred birth spacing}

Table 7: Preferred birth spacing

\begin{tabular}{|l|l|l|}
\hline Preferred Birth spacing & Frequency & Percentages(\%) \\
\hline After one year & 60 & 30 \\
\hline After two years & 40 & 20 \\
\hline After three years & 26 & 13 \\
\hline Four years and above & 44 & 22 \\
\hline Undecided & 30 & 15 \\
\hline Total & 200 & 100 \\
\hline
\end{tabular}

Source: Author’s field survey, March, 2014

Asked when they would like to have the next child, it is interesting to observe in the table that a sizeable proportion (22\%) of the mothers preferred long birth spacing of four years and above. This was followed by only 13 percent and 20 percent citing birth spacing of three and two years respectively. It is notable that a high proportion (15\%) of the mothers was indecisive in regard to the time they would like to have the next baby.

\section{Postpartum pregnancy risk perception}

Majority of the respondents (70\%) did not think that they would be at risk of pregnancy during the first year after giving birth, compared to a smaller proportion (30\%) who perceived the risk of pregnancy in the postpartum period.

\section{Reasons for positive pregnancy risk perception}


South American Journal of Clinical Research Special Edition 2016

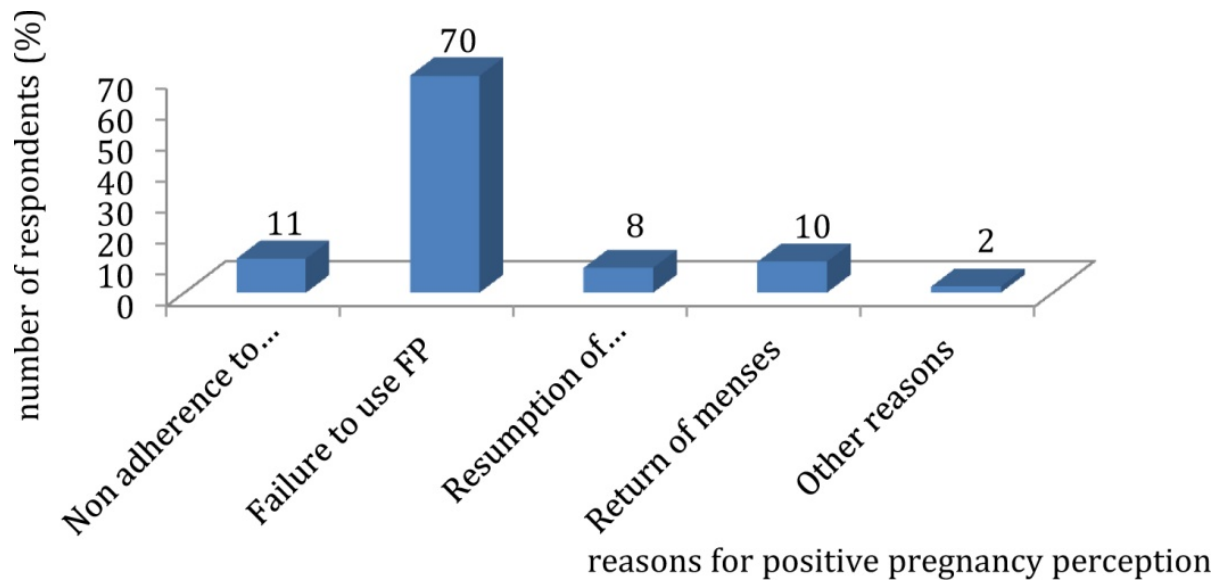

Figure 9: Reasons for positive pregnancy risk perception

Source: Author's field survey, March, 2014

The leading reason expressed by $70 \%$ of the mothers was failure to use a family planning method in the postpartum period, followed by concerns regarding return of menses (10\%). About 11 percent cited failure to adhere or follow family planning method instructions while resumption of sexual activity was reported by 8 percent. Only 2 percent did not give a specific reason.

\section{Reasons for non-perception of postpartum pregnancy risk}

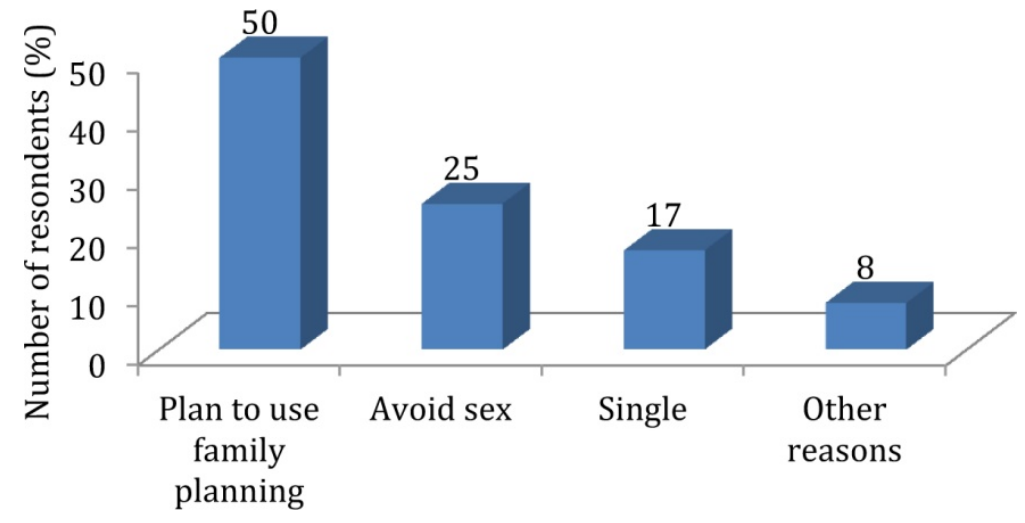

Figure 10: Reasons for non-perception of postpartum pregnancy risk

Source: Author's field survey, March, 2014

The main reason given was plan to use family planning to prevent pregnancy (50\%) which was followed by avoiding sex in the postpartum period (25\%). About 17 percent cited being single while 8 percent gave other reasons such as baby being small, having learnt from their mistakes etc. 


\section{Reference group used by respondents to make decision on FP}

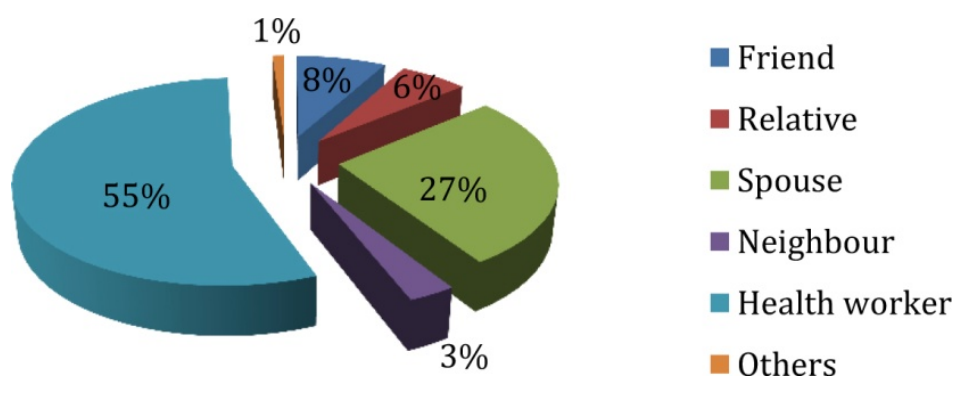

Figure 11: Reference group used by respondents to make decision on FP

Source: Author’s field survey, March, 2014

Figure10 shows that a substantial proportion preferred to seek advice on PPFP from health workers (55\%), followed by $27 \%$ who preferred to discuss with spouses. About 8 percent would like to consult friends while 6 percent preferred to talk with relatives. Only 3 percent cited neighbors while 1.0 percent of the respondents were not specific.

\section{Intention to use postpartum family planning}

\section{Intention to use PPFP}

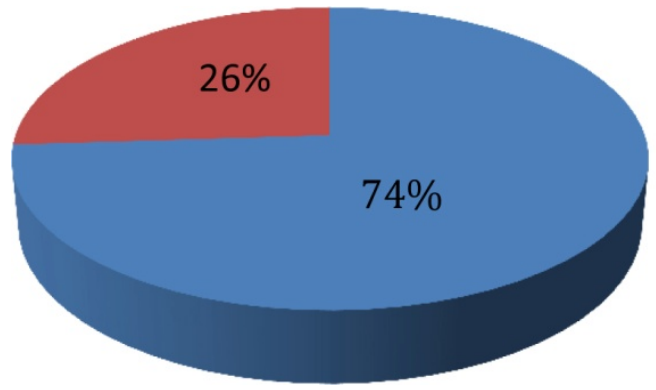

Intent to use PPFP

No intention to use

PPFP

Figure 12: Respondent's intention to use PPFP

Source: Author's field survey, March, 2014

A high proportion of 74 percent reported plans to use PPFP as can be seen on figure11. Only 26 percent reported having no intentions to use family planning in the postpartum period.

\section{Preferred PPFP method}

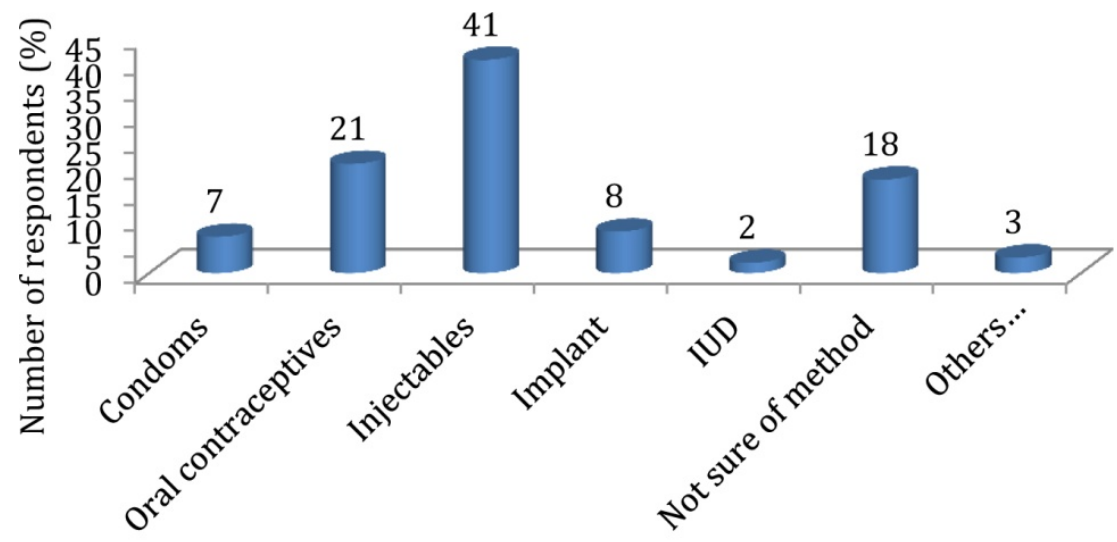

Methods 
South American Journal of Clinical Research Special Edition 2016

Figure 13: Respondent's preferred PPFP method

Source: Author’s field survey, March, 2014

The majority of the respondents chose to use injectable contraceptives (41\%), followed by pills (21\%), implants (8\%) and intrauterine devices $2 \%$. Only 7 percent choose to use condoms while 3 percent settled for herbs and calendar methods. However, it is notable that a sizeable proportion of the first time mothers were not sure of the method to use (18\%), even though they had the intention to use contraceptives in the postpartum period.

\section{Reason for the preferred PPFP method.}

Table 8: Reasons for the preferred PPFP methods

\begin{tabular}{|l|l|l|}
\hline Reason & Frequency & Percentages(\%) \\
\hline Convenient for 3 months & 26 & 13 \\
\hline Few side effects & 18 & 9 \\
\hline Cannot forget & 28 & 14 \\
\hline Satisfaction with prior use & 14 & 7 \\
\hline Has heard its good & 52 & 26 \\
\hline Easy to use & 30 & 15 \\
\hline Long term protection & 16 & 8 \\
\hline Prevent STI & 8 & 4 \\
\hline Don't know & 8 & 4 \\
\hline Total & 200 & 100 \\
\hline
\end{tabular}

Source: Author’s field survey, March, 2014

Most of the reasons given for the preferred PPFP method were method related, such as convenient to use (13\%), cannot forget(14\%), few side effects(9\%), long term protection(8\%), easy to use(15\%). However, a substantial proportion of those who had the intention to use PPFP was not knowledgeable on the pros and cons of the various contraceptive methods but claimed they heard it was good (26\%). $4 \%$ could not give a specific reason for their preference.

\section{Preferred PPFP adoption period}

Table 9: Preferred PPFP adoption period

\begin{tabular}{|l|l|l|}
\hline Adoption period & Frequency & Percentages (\%) \\
\hline Less than 6 weeks after delivery & 22 & 11 \\
\hline
\end{tabular}




\begin{tabular}{|l|l|l|}
\hline 6 weeks after delivery & 78 & 39 \\
\hline More than 6 weeks after delivery & 80 & 40 \\
\hline Not sure & 20 & 10 \\
\hline Total & 200 & 100 \\
\hline
\end{tabular}

Source: Author’s field survey, March, 2014

The majority of the mothers preferred to adopt PPFP more than six weeks after delivery (40\%), while an almost equal proportion cited adoption at six weeks after delivery (39\%). About 11 percent wanted to adopt PPFP before six weeks after delivery while only 10 percent were not sure of when to adopt the method and preferred to be advised by the health worker.

\section{Reasons for not intending to use PPFP}

Table 10: Reasons for not intending to use PPFP

\begin{tabular}{|l|l|l|}
\hline Reason & Frequency & Percentages (\%) \\
\hline Fear of side effects & 80 & 40 \\
\hline Not married & 30 & 15 \\
\hline Plan to abstain/avoid sex & 44 & 22 \\
\hline Don't know FP methods & 6 & 3 \\
\hline Religious restrictions & 14 & 7 \\
\hline Consult spouse & 26 & 13 \\
\hline Total & 200 & 100 \\
\hline
\end{tabular}

Source: Author’s field survey, March, 2014

Table7 shows the main reason given was fear of side effects (40\%). Respondents who cited plans to avoid sex or abstain accounted for 22 percent while those who gave reason of being single were 15 percent. About 3 percent reported lack of knowledge on PPFP methods, religious restriction (7\%) and need to consult spouse accounted for 13percent.

\section{Differences in the intention to use postpartum family planning}

\section{Intention to use PPFP according to socio-demographic factors}

Table 11: Intention to use PPFP according to socio-demographic factors

\begin{tabular}{|l|l|l|}
\hline Socio-demographic variables & Yes (\%) & $\begin{array}{l}\text { No } \\
\text { (\%) }\end{array}$ \\
\hline Age group & 85 & 15 \\
\hline
\end{tabular}


South American Journal of Clinical Research Special Edition 2016

\begin{tabular}{|l|l|l|}
\hline $15-34$ & & \\
\hline $35-49$ & 60 & 40 \\
\hline Education level & 72 & 28 \\
\hline Primary & 87 & 13 \\
\hline Secondary & 95 & 5 \\
\hline Tertiary & & \\
\hline Religion & 93 & 7 \\
\hline Catholic & 80 & 20 \\
\hline Protestant & 77 & 23 \\
\hline Muslim & & \\
\hline Marital status & 74 & 26 \\
\hline Never married & 99 & 1 \\
\hline Married & 89 & 11 \\
\hline Occupation & 94 & 6 \\
\hline Student & 89 \\
\hline Unemployed & & \\
\hline Employed & & \\
\hline
\end{tabular}

Source: Author’s field survey, March, 2014

The table shows that the mothers aged between 15 and 34 had a higher intention to use PPFP (85\%) than the mothers aged 35 years and above (60\%).

A very high proportion of educated mothers had intentions to use PPFP with small variations between those with primary (72\%), secondary (87\%) and tertiary education (95\%).

Religious beliefs influence adoption of modern family planning. The data shows that the Catholic mothers had the highest intention to use PPFP (93\%) while the Muslim mothers reported the lowest intention to use PPFP (77\%). It is surprising that Catholics who are expected to be more conservative than Protestants reported more intention than the latter.

Furthermore, mothers who were not in any form of employment had a higher intention to use PPFP (89\%) than those in employment (81\%). Also mothers who were still in school had the highest intention to use PPFP (94\%).

Almost all married mothers (99\%) had intentions to use PPFP, which is much higher than 74\% percent of the women who had never married. 
Intention to use PPFP by other selected variables

Table 12: Intention to use PPFP by other selected variables

\begin{tabular}{|l|l|l|}
\hline Variable & Yes (\%) & No (\%) \\
\hline Contraceptive Knowledge & & \\
\hline Don't know & 56 & 44 \\
\hline Know 1-2 methods & 92 & 8 \\
\hline Know 3-4 methods & 93 & 7 \\
\hline Know 5-6 methods & 90 & 10 \\
\hline Contraceptive prior use & & \\
\hline Ever used & 87 & 13 \\
\hline Never used & 79 & 21 \\
\hline ANC attendance & & \\
\hline One visit & 65 & 35 \\
\hline Two visits & 76 & 24 \\
\hline Three visits & 81 & 19 \\
\hline Four visits and above & 92 & 8 \\
\hline Prenatal contraceptive counseling & & \\
\hline Counseled on FP & 92 & 8 \\
\hline Not counseled on FP & 90 & 10 \\
\hline Current pregnancy wanted & 93.2 & 13.8 \\
\hline Wanted & 84.5 & 5.5 \\
\hline Not wanted & & \\
\hline Preferred birth spacing & & \\
\hline 2 years and above & & \\
\hline Undecided & & \\
\hline
\end{tabular}


South American Journal of Clinical Research

Special Edition 2016

\begin{tabular}{|l|l|l|}
\hline Postpartum pregnancy risk & & \\
\hline Risk perceived & 92 & 8 \\
\hline No risk perceived & 89 & 11 \\
\hline Reference group & & \\
\hline Friend & 88 & 12 \\
\hline Relative & 62 & 38 \\
\hline Spouse & 83 & 11 \\
\hline Health worker & 94 & 6 \\
\hline
\end{tabular}

Source: Author’s field survey, March, 2014

The table shows that over 90 percent of mothers who knew at least one method had intention to use PPFP. On the other hand, those who did not know any FP method had much lower intention (56\%).

The findings show that almost all mothers who have used contraceptives in the past had higher intention to use PPFP (87\%), which is higher than those who had never used (79\%). Results also indicated that the mothers who attended four or more antenatal visits had the highest intention to use PPFP (93\%) while those who attended ANC twice or once had the lowest intention to use PPFP. The table also shows that mothers who had received prenatal contraceptive counseling had slightly higher intention to use PPFP (92\%) than those who had not received family planning counseling during pregnancy (90\%).

Table 10 shows that the mothers who had planned for the current pregnancy had a higher intention to use PPFP (93\%) than those who had not planned for the current pregnancy (84\%). Results in Table 5.7 indicates that mothers who perceived the risk of pregnancy in the postpartum period had slightly higher intention to use PPFP (92\%) than those who did not perceive the risk (90\%).

Mothers who preferred to consult health workers on family planning matters had highest intention to use PPFP (94\%) while those who preferred to consult relatives had the lowest intention to use PPFP (62\%). Ninety three percent and 88 percent preferred to consult spouses and friends respectively.

\section{Discussion and conclusion}

Knowledge of Family Planning: Family planning (FP) is an essential component of health care provided during the antenatal period, immediately after delivery and during the first year postpartum (WHO,2008). Postpartum family planning is the prevention of unintended and closely spaced pregnancies through the first 12 months following childbirth(McKaig and Dellar, 2006; WHO, 2006).

The knowledge of family planning is almost universal as $97 \%$ of the respondents have heard about family planning. All the respondents who have heard of family planning know at least a modern family planning method. This is comparable with the findings in the Ghana Demographic and Health Survey (2008), where 98\% of married women know of at least one modern contraceptive method. The study is supported by that of Kariuki (2011) who found in his 
study on factors determining the intension to use postpartum family planning among the first time mothers in Kenya that 95.6 knew at least one modern contraceptive method.

The findings in this study also compares with the findings in a Demographic Study of Gujjars of Delhi on the knowledge, attitude and practice of family planning in ever-married Gujjar women aged 15-49 years from a sample of 558 households where knowledge of contraceptive methods is nearly widespread among ever married Gujjar women (Day et al., 2008)

The findings are also consistent with research conducted by Manandhar et al., (2012), which showed that $100 \%$ of the respondents had heard about at least one method of family planning. The findings of this study are also comparable with a study on knowledge, attitude and practice of family planning: A Study of Tezu Village, Manipur (India), which found that the knowledge of family planning is widespread among the respondents and the respondents know of at least one method of contraception (Mao, 2007).

Relationship Between the Knowledge and Practice of Family Planning: From our study, 97\% of the respondents have heard about family planning and know at least one family planning method but only $30 \%$ of the respondents were currently practicing family planning. This is quite on a low side, considering that with a very high knowledge about a methods, it would have been expected that the current usage rate would have been higher. This shows that a wide gap exists between the knowledge and practice of family planning.

Onwuzurike and Uzochukwu,(2001), had comparable results in their study on the knowledge, attitude and practice of family planning amongst women in a high density low income urban area of Enugu, Nigeria, where knowledge and approval of family planning was high, $81.7 \%$ and $86.2 \%$ respectively, but the practice of family planning was low, as only $20 \%$ of the women were on a family planning method. It is concluded that despite their high level of education/literacy, with the attendant high knowledge and approval rate of family planning, the proportion of women using modern family planning methods was low in this part of Nigeria.

Studies by Kumssa et al (2013) on assessment of knowledge, attitude and practice among women of child bearing age towards contraceptive drug utilization also agree with our findings on the knowledge but differs on the utilization. Kumssa et al (2013) found that out of 361 interviewed women in childbearing ages, 347(96.2\%) of them knew about family planning method. The majority of the women in childbearing ages interviewed showed that 330(94.2\%) of them were experienced to use contraception methods.

Low utilization of the finding is also in agreement with the study in Tanzania on utilization of modern family planning methods among women of reproductive age in Shinyanga rural district of Tanzania. Anna and Nassoro (2006) found that more than half of the women (56.5 percent) had low level of knowledge of the methods and the use rate was low, 12.2 percent. Despite increased knowledge about family planning and positive attitudes towards it among both the general public and policy makers, utilization rates of contraceptives have remained fairly static over time.

Source of Information: From our study, the most frequent source of information about family planning is health talks in the clinics (38.2\%), followed by community health workers (23.7\%) and from peers (23.7\%). The mass media and other books (14.4\%).

However, according to the 2013 Ghana Demographic and Health Survey, radio is the most frequent source of family planning message (77\%), followed by television (52\%), health workers (47\%), community meetings (34\%) and newspapers (20\%).

Findings by Adinma (2002), also differ from our findings, with the printed media being the most frequent source of information (47.9\%), while the least common was lecture/sex instruction, (11.5\%). 
South American Journal of Clinical Research

Special Edition 2016

The major sources of information on family planning were television and radio (mass media) accounting for $57.1 \%$, Doctors, nurses and family planning workers, 24.4\%; with friends and relatives accounting for $18.5 \%$ in a study by Day et al., (2008) .This also does not correspond with our findings.

Reasons for Non-Usage: In spite of the high level of knowledge, why is it that only a small proportion of the respondents are currently using these methods?

Among those who are not practicing family planning, fear of side effects (40\%), plans to avoid sex or abstain accounted for 22 percent while those who gave reason of being single were 15 percent. About 3 percent reported lack of knowledge on PPFP methods, religious restriction (7\%) and need to consult spouse accounted for 13percent.

There is a correlation with the study by Hani et al., (2007), which showed that fear of contraceptive side effect is identified as one of the most important explanations for non-use. However, the risk of contraceptive side effect are relatively low compared to the risk of a typical pregnancy and especially to that of unintended pregnancy because a number of such pregnancies are terminated by unsafe induced abortion in developing countries especially. The mortality risk of an unintended pregnancy comes 20 times the risk association with the use of a modern method of contraception.

According to 2013 Ghana Demographic and Health Survey, fear of side effects has increased in importance as a reason for non-use since 1998, from 18 to 26 percent.

The finding of the study by Onwuzurike and Uzochukwu (2001), differs from our findings where the commonest single reason for non-practice of a method was rejection by the husband.

The reasons for non-use of contraceptive methods were: refusal by husbands (54\%), the belief that the methods "cause infertility and ill-health" (35\%) and that it was against their religion (28\%) in a study by Hani et al., (2007) which also differs from our findings.

In a study by DaVanzo (2004), among women who have never used contraceptives, the most commonly mentioned reason (over two-fifth) for not using a method is the desire to have more children. Over ten percent report that they are not using contraceptives because they are menopausal. One in six women mentions opposition of their husband to the use of contraception. Other minor reasons that are cited for not using contraceptives are health related problems, afraid of sterilization and worry about side effects. Less than ten percent believe that if one continues to use contraceptives, it is difficult to get pregnant if the contraceptive is discontinued. These findings do not correspond to our findings.

Influence of Prenatal Contraceptive Counseling on Intention to use PPFP.: From the study, it is interesting to discover that $62 \%$ of the respondents attended antenatal care, however less than half (38\%) of the postnatal mothers had been given any information about counseling as well as PPFP during the antenatal visit. Of those who had prenatal contraceptive counseling, high proportion of $74 \%$ reported as having plans to use PPFP. Only $26 \%$ reported having no intention to use family planning in the postpartum period. This finding demonstrate that prenatal contraceptive counseling has a positive influence on postpartum mothers as per use of PPFP.

This finding is in agreement with study by Barber (2007); Depiners et al.,(2005); Ross and Winfery (2001); Glasier et al (1996) that women who receive family planning advice during prenatal care were more likely to use a contraceptive than those who did not receive such advice and that antenatal period provided a golden opportunity to discuss not only the appropriateness of the choosen contraceptive but also its correct use.

The findings also is consistent with study of King (2007); Glasier et al. (1996) that prenatal care provide opportunities to discuss pros and cons of each contraceptive option, which helps the woman to make an informed decision on the most appropriate choice to adopt after birth Day et al.(2008) stated that prenatal period increases provider-patient interaction and offers multiple 
opportunities for family planning decisions and education. This also goes in accord with the finding of this study.

Conclusion: Mothers' education and marital status are the main factors affecting the use of family planning. Education exposes the mothers to information on methods of birth control and increases understanding on various aspects of contraceptives such as mechanism of action, method specific instructions and side effects. The years spent in school also delay start of childbearing and enable the women to make informed decisions in matters affecting their reproductive health at a mature age. Marriage exposes mothers to sexual intercourse in the postpartum period and increases the risk of conception. Consequently, the married mothers have a higher intention to use PPFP than their unmarried counterparts. This means that their needs for PPFP should be addressed to ensure their intentions translate into actual use, which will reduce the unmet need for PPFP in KATH.

Recommendations: Based on our findings, the following recommendations are put forth:

\section{Roles of government and policy makers}

Based on the above findings, several policy recommendations are suggested. Firstly, effort should be made by the Ghana government and its partners to improve the quality of knowledge on contraceptive methods recommended for postpartum family planning, to enable mothers to make informed choices. This could be through enhanced social marketing and maternal and child health services such as ANC, immunizations and postnatal clinics.

Secondly, there is need to strategize girls education to ensure that majority attain at least secondary education. Incorporation of adolescent and youth reproductive health through school based model will also go a long way in reducing early school dropout and early marriages in addition to promoting their reproductive health.

Thirdly, the Ghanaian government should facilitate policies that can strengthen and stabilize the institution of marriage; such as promoting formal marriages. Likewise programs that encourage involvement of spouses in reproductive health decision making would facilitate translation of intention to use PPFP into actual use among the married mothers.

Recommendations for further comparative research on the factors affecting the use of PPFP among mothers living in the rural setting, since the current study was done in an urban setting. There is need for future research into the role of school based adolescent and reproductive health Model as an entry point in creating awareness on fertility control.

\section{Role of staff and student nurses of KATH}

The staff and students should place strong emphasis on information dissemination, education and communication especially person-to-person counseling by the health workers and group discussions. The staff should also increase the level of counseling as people normally venture to do activities they understand.

They should ensure that locations, days, hours and kinds of methods offered are well explained so that services are available and convenient to all who need them.

\section{References}

[1]. Anna, T., and Nassoro, R. (2006) Utilization of Modern Family Planning Methods Among Women of Reproductive Age in Rural Setting: The Case of Shinyanga Rural District, Tanzania. East African Journal of Public Health, Vol.3 No.2, pp.26-30.

[2]. Adinma B.(2002) An overview of the global policy consensus on women's sexual and reproductive rights: The Nigerian perspective. Tropical Journal of Obstetrics Gynaecology Vol.1No.1, pp.9-12.

[3]. Barber, L.S. (2007). Family planning advice and postpartum contraceptive use among low-income women in Mexico. International Family Planning Perspectives, 33(1): 6-12 
South American Journal of Clinical Research Special Edition 2016

[4]. DaVanzo, J. (2007) Effects of interpregnancy interval and outcome of the preceding pregnancy on pregnancy outcome in Matlab, Bangladesh. BJOG, 114(9): 1079-1087

[5]. Day, T., Raker, C.A., and Boardman, L.A. (2008).Factors associated with the provision of antenatal contraceptive counseling. Contraception, 78(4): 294-299.

[6]. Depineres, T., Blumenthal, P.D and Diener-West, M. (2005). Postpartum contraception: the New Mexico pregnancy risk assessment monitoring system. Contraception, 72(6): 422- 425.

[7]. Ghana National Bureau of Statistics(2010) Ghana Demographic and Health Survey 2008-13

[8]. Glasier, A.F., Logan, J., and McGlew, T.J. (1996).Who gives advice about postpartum contraception? Contraception, 53(4): 217-220.

[9]. Hani,A., Moss, M., Cooper, D., Morroni, C \& Hoffman, M. (2007).Informed choice-the timing of postpartum contraceptive initiation. South Africa Medical Journal, 93(11): 862-864.

[10]. Kariuki, W.D. (2011) Factors determining the intension to use postpartum family planning among the first time mothers aged 15-29 years in Kenya. Retrieved from: www.docs.mak.ac.ug/sites/default/files/DAINAH\%20DISSERTATION.doc

[11]. King, J. (2007). Contraception and lactation. Journal of Midwifery and Women’s Health, 52(6):614-620.

[12]. Kumssa, E., Kahaliw, W., and Ergetie, Z. (2013) Assessment of Knowledge, Attitude and Practice Among Women of Child Bearing Age Towards Contraceptive Drug Utilization in Adama (Kebele 12). International Journal of Medical and Pharmaceutical Sciences, 3 (10), 01-08.

[13]. Mao J. Knowledge, Attitude and Practice of Family Planning: A Study of Tezu Village, Manipur (India). The Internet Journal of Biological Anthropology 2007; 1(1); 45-52

[14]. Manandhar N, Singh SK, Patowary S, Krishna G.(2012) Study of knowledge, attitude and practice of family planning in an urban area of Bharatpur. Journal of Institute of Medicine Vol. 28(2); 35-44

[15]. McKaig, C and Deller, B. (2006).After the fact: family planning for the postnatal period. ACCESSFP/JHPIEGO.http://www.maqweb.org/miniu/present/2006/After\%20the\%20Fact- PPFP.ppt

[16]. Onwuzurike B.K, and Uzochukwu B.C. Knowledge, Attitude and Practice of Family Planning amongst Women in a High Density Low Income Urban of Enugu, Nigeria. African Journal of Reproductive Health 2001; 5(2); 83-89.

[17]. Ross, A.J., and Winfrey, W.L. (2001).Contraceptive use, intention to use and unmet need during the extended postpartum period. International Family Planning Perspective, 27(1):20-27.

[18]. Salway, S., and Nurani, S. (1998).Uptake of contraception during postpartum amenorrhea: understandings and preferences of poor, urban women in Bangladesh. Social Science and Medicine, 47(7): 899-909.

[19]. World Health Organization, Pregnancy, Childbirth, Postpartum and Newborn Care: A Guide to Essential Practice, 2006.

(http://www.who.int/reproductivehealth/publications/maternal_perinatal_health/9241590 84X/en/. Accessed on 27 January 2014).

[20]. World Health Organisation. Selected Practice Recommendations for Contraceptive Use. 2nd edition and 2008 update

(http://www.who.int/reproductivehealth/publivcations/family_planning/9241562846index en/index.html. Accessed on 27 January 2014). 